\title{
İplik işletmeleri iklimlendirme sektöründe kullanılan pleyt üzerindeki akışın sayısal olarak incelenmesi
}

\section{Numerical investigation of flow on plate used in the air conditioning sector of yarn production facilities}

\author{
Emrah Gönen",* (i), Ahmet Kaya ${ }^{2}$ (D) \\ ${ }^{1,2}$ Kahramanmaraş Sütçü İmam Üniversitesi, Makine Mühendisliği Bölümü, 46100, Kahramanmaraş, Türkiye
}

\begin{abstract}
Özet
İplik fabrikalarında üretimin kaliteli ve kesintisiz olabilmesi için havanın şartlandırılarak üretim alanına homojen bir şekilde dağıtılması son derece önemlidir. İklimlendirilmiş havanın ortama homojen olarak yayılması ise üfleme menfezlerine konumlandırılan pleytler aracılığı ile sağlanmaktadır. Bu çalışmada, bir iplik işletmesinde halihazırda kullanılan pleyt üzerindeki akış incelenmiştir. Mevcut pleyt üzerinden olan akışı iyileştirmek için üç yeni tasarım geliştirilmiştir. Pleytler üzerindeki hava akışının homojenliği ve ortam havasına etkisi sayısal olarak incelenmiştir. Sayısal analiz sonuçları karşılaştırılarak optimum pleyt tasarımı belirlenmiştir.
\end{abstract}

Anahtar kelimeler: Tekstil, İklimlendirme, Pleyt, Hava kanalı, Akış analizi.

\section{Giriş}

İplik üretiminde ortaya çıkabilecek olası üretim kusurlarını ortadan kaldırmak için iplik üretim tesislerinin iklimlendirilmesi gerekmektedir. Pamuk elyafı iplik olana kadar çekme, sarma, birleştirme gibi çok sayıda işlemden geçer ve bu işlemler sırasında toz ve uçuntu açı̆̆a çıkar. İpliğe mukavemet kazandırmak için salon ortamının doğru şartlandırılmış olması ve şartlandırılan havanın ortama homojen dağıtılması gerekir. Dolayısıyla ipliğe mukavemet vermek, salon havasını temizlemek ve uçuntuları toplamak amaciyla, iplik üretim tesislerinde bir klima tesisine ihtiyaç duyulmaktadır.

Tekstil kliması uygulamalarında genellikle 100000 $200000 \mathrm{~m}^{3} / \mathrm{h}$ gibi yüksek debilere ihtiyaç duyulmaktadır. Tekstil klimasında, genelde aspiratör kullanılarak zemin altındaki kanallar vasitasıyla salon havası toplanır. Toplanan kirli hava temizlenmek üzere "döner filtre ünitesine" gönderilir. Burada filtreden geçirilerek temizlenen hava, eksenel fanlar vasitasılya nemlendirme hücresine gönderilir ve hava içerisine su püskürtülür. Böylece, evaporatif soğutma yoluyla nemlendirilen hava, bir vantilatör vasıtasıyla nemlendirme hücresinden alınır ve işletme tavanına yerleştirilmiş üfleme kanallarına bağlı menfezler ile ortama sevk edilir. İklimlendirilmiş hava, kanallar üzerine monte edilen "pleytli üfleme menfezleriyle" ortama üflenir

\begin{abstract}
In order to ensure quality and uninterrupted production in spinning mills, the homogeneous distribution of conditioned air delivered to the directly affects the efficiency and quality of yarn production. The homogeneous distribution of the conditioned air to the environment is provided by the plates in the grilles. In this study, three different plate structures have been designed by examining the wing structures and angles of the plates used in the blowing channels of the spinning mills. The homogeneity of the air flow on the plates and its effect on the ambient air have been examined numerically. The optimum plate design has been revealed by comparing the numerical analysis results.
\end{abstract}

Keywords: Textile, Air conditioning, Plate, Air duct, Flow analysis.

ve çevrim bu şekilde devam eder. Havanın, ortama homojen şekilde dağıtılması iplik üretiminin verim ve kalitesini doğrudan etkilemektedir. Havanın ortama homojen olarak yayılması ise pleytler aracılığı ile sağlanmaktadır.

Literatürde, iklimlendirme sistemlerinde akışın yönlendirilmesi konusunda birçok sayısal çalışma yapılmış ve bunlardan bazıları incelenerek aşağıda verilmiştir.

Yıldırım vd. [1] bir odanın havalandırmasında kullanılan slot difüzör ve jet nozulun oda içindeki yerleşim poziyonunu ANSYS ile belirlemişlerdir. Jet nozulun atış mesafesinin yüksek olduğunu, slot difüzörde ise havanın perde şeklinde ve hızlı indiğini, difüzörün altında bulunanların bundan olumsuz etkilendiğini ve bu nedenle slot difüzörlerin tavan yüksekliği fazla olan yerlerde tercih edilmesinin daha uygun olduğunu tespit etmişlerdir.

Kaya vd. [2] merkezi klima santralleri için tasarlanan düz ve piramit şekilli anemostat tip difüzörün boş hücrede oluşturduğu akış ve basınç düşümünü ANSYS programı ile araştırmışlardır. Düz yapıya sahip anemostat tip difüzörün $80^{\circ}$ kanat açısında hava akışının daha homojen şekilde yayıldığını tespit etmişlerdir.

Sönmez vd. [3] kesik konik tip profile sahip delikli difüzör yapısının akış dağılımı ve basınç düşümüne etkisini ANSYS programında sayısal olarak incelemişlerdir. Akışı iyileştirmek amacı ile farklı delik geometrili difüzörler

\footnotetext{
* Sorumlu yazar / Corresponding author, e-posta / e-mail: emrah.gonen@ outlook.com (E. Gönen)

Geliş / Recieved: 25.12.2020 Kabul/ Accepted: 11.08.2021 Yayımlanma / Published: 14.01.2022

doi: $10.28948 /$ ngmuh. 846854
} 
tasarlamış ve akışa etkisini sayısal olarak incelemişlerdir. Delik geometrisinin kare olduğu difüzör tipinin delik geometrisi altıgen ve daire olduğu difüzör tipine göre basınç düşümünün daha yüksek olduğunu tespit etmişlerdir.

Yiğit vd. [4] piyasada kullanılan standart tip difüzörlerden farklı olarak, akışı homojenize edebilme özelliği yüksek bir difüzör tasarlamışlardır. $0^{\circ}-55^{\circ}$ arasında değişen düşey kanat açılarına sahip olan difüzör yapılarının akış dağıtıcılığını ANSYS programında sayısal olarak incelemişlerdir. Düşey kanat açısı $45^{\circ}-55^{\circ}$ arasındaki difüzör tasarımlarının havalandırılan ortamdaki havanın homojen şekilde dağıtılmasını sağlamakta olduğunu ve bu kanat açılarına sahip difüzörlerin ortamda oluşan hava hızı açısından değerlendirildiğinde konfor şartlarına en uygun difüzörler olduğu sonucuna ulaşmışlardır.

Patel ve Dhakar [5] bir oda içerisindeki üç farklı klima konumunun 1sil konfora etkisini sayisal olarak incelemişlerdir. Klima konumunun tavanda olması durumunda en iyi soğutmanın sağlanacağını ve klimanın soğutma süresinin kısaldığını tespit etmişlerdir.

Kuas ve Başkaya [6], içerisinde insan ve nesnelerin bulunduğu bir ofis ortamına sevk edilen soğuk havanın, ortam hacmindeki akışını sayısal olarak incelemişlerdir. Menfez ve hacim içindeki nesne konumlarının hava hareketine ve insan konforuna etkisini araştırmışlardır. Havalandırılan hacmin boş veya değişik nesnelerle ve insanla dolu olmasının oda içerisindeki hava akış yapısını önemli derecede etkilediğini tespit etmişler ve bu tür çalışmalarda insan ve nesnelerin dikkate alınması gerektiğini vurgulamışlardır.

Öntaş [7], kapalı bir ofis hacmi içerisinde hava dağılımına, yarık tipli menfez (slot difüzör) ve kare menfezlerin etkisini deneysel ve sayısal olarak incelemiştir. Yarık tipli havalandırma menfezi ve kare tipli havalandırma menfezi ile yapılan çalışmalar karşılaştırıldığında yarık tipli menfez yapısının tavana yakın yerlerde daha etkin bir hava akışına neden olmasına rağmen zemine yakın yerlerde hava hızlarının kare tip menfez ile gerçekleştirilmiş olan çalışmaya göre daha düşük kaldığını, bu durumun ise konfor koşulları göz önünde bulundurulduğunda esintisizliğe ve sonuç olarak insanlarda rahatsızlığa neden olabileceğini tespit etmiştir.

Yüce ve Pulat [8], bir ofis ortamındaki hava akışını türbülans kinetik enerjisi ve sıcaklık dağılımlarını havalandırma verimliliğini tahmin edebilmek amacıyla incelemişlerdir. Analizler farklı giriş sıcaklıkları (298, 300 ve $303 \mathrm{~K})$ ve farklı giriş hızları $(1.5,2.0$, ve $3.0 \mathrm{~m} / \mathrm{s})$ içeren dokuz farklı şart için gerçekleştirilmiştir. Çalışma sonucu elde ettikleri verilerle havalandırma sistemi giriş koşullarının 1sıl konfor ve havalandırma verimliliği üzerindeki etkilerini tespit etmeye çalışmışlardır. Mevcut şartlarda $2 \mathrm{~m} / \mathrm{s}$ hava giriş hızı ve $303 \mathrm{~K}$ hava giriş sıcaklığına sahip bir havalandırma sisteminde homojen sıcaklık dağılımı elde etmenin mümkün olabileceği sonucuna ulaşmışlardır.

Canpolat vd. [9] bir oda içerisinde bulunan klimanın, hava üfleme doğrultusunun $\left(10^{\circ}, 30^{\circ}, 50^{\circ}, 70^{\circ}\right)$ oda içindeki sıcaklık ve hız dağılımına etkisini ANSYS programında sayısal olarak incelemişlerdir. Oda içerisindeki hız, sıcaklık ve türbülans yoğunluğuna bağlı olarak meydana gelen cereyanın etkisini ifade etmek amaciyla yüzde memnuniyetsizlik (PD) değeri yapılan çalışmada ısıl konfor parametresi olarak tanımlanmıştır. Dört farklı üfleme doğrultusunda $\left(10^{\circ}, 30^{\circ}, 50^{\circ}, 70^{\circ}\right)$ farklı noktalardaki XY kesitleri için elde edilmiş olan PD dağılımları dikkate alındığında üfleme doğrultusu $70^{\circ}$ olduğunda daha az bölgede cereyan oluştuğu ve mevcut şartlarda en uygun üfleme açısının $70^{\circ}$ olduğunu tespit etmişlerdir.

Awwad vd. [10] kare geometriye sahip beş kanatlı tavan difüzörünün kanat $\left(65^{\circ}, 60^{\circ}, 45^{\circ}\right)$ ve dudak $\left(0^{\circ}, 5^{\circ}, 10^{\circ}, 15^{\circ}\right)$ açılarını değiştirerek bir oda içerisindeki akışı sayısal olarak incelemişlerdir. $65^{\circ}$ kanat açılı difüzör yapısının daha geniş alana sahip ortamlarda kullanılması gerektiğini, bu kanat açısında konfor koşullarına daha hızlı ulaşıldığını fakat enerji tüketiminin ve gürültü seviyesinin arttığını, $45^{\circ}$ kanat açısının ise tavan yüksekliğinin fazla olduğu ortamlarda kullanılmasının uygun olacağını tespit etmişlerdir. Ayrıca $15^{\circ}$ dudak açısında akışın tavanda daha fazla tutunduğunu ve enerji tüketimini diğer dudak açılarına sahip difüzörlere göre önemli derecede düşürdüğü sonucuna ulaşmışlardır.

$\mathrm{Bu}$ çalışmada ise, iplik üretim tesisinde kullanılan pleytler üzerinde sayısal analiz çalışmaları yapılmıştır. Mevcut pleyt üzerinde, homojen akış elde etmek amacıyla tasarım iyileştirmeleri yapılarak üç farklı pleyt tasarımı geliştirilmiştir.

\section{Materyal ve metot}

$\mathrm{Bu}$ çalışma, Kahramanmaraş ilinde bulunan TEMSAN Makina ve Tekstil San. Tic. A.Ş. bünyesinde kullanılan pleyt problem olarak ele alınmış olup mevcut durumda kullanılan pleyt geometrisinden kaynaklı problemlerin çözümüne yönelik çalışmalar gerçekleştirilmiştir. Firma iplik üretim ve dokuma tesislerinde kullanılmak üzere tekstil klima sistemleri ve bu sistemlere yönelik tamamlayıcı ürünlerin üretim ve imalatını gerçekleştirerek otomasyon ve yazılımını kendi bünyesinde yapmaktadır. Sayısal çalışmada kullanılan hız değerleri, çalışan bir iplik üretim tesisinin ring klimasının üfleme menfezlerinden ölçülerek alınmıştır.

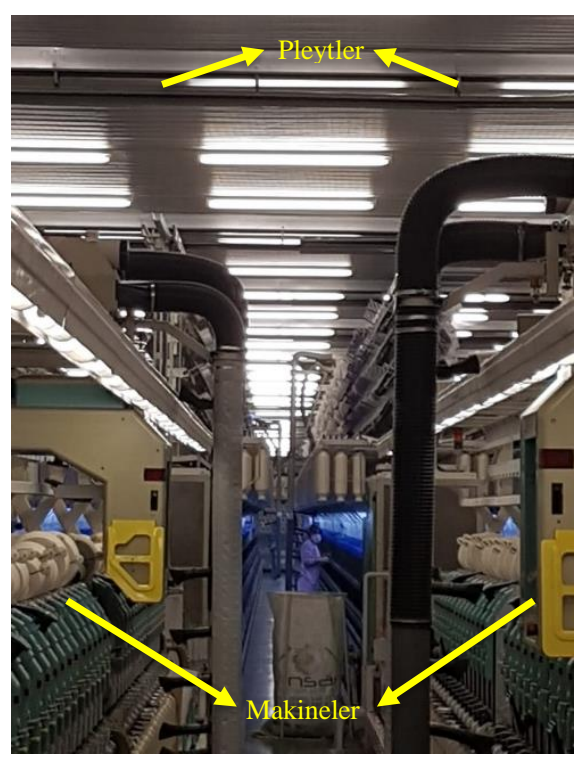

Şekil 1. İplik üretim tesisi 
Ring fitil halindeki pamuğu inceltip büküm vererek mukavemetini artırarak masuraya saran makineye verilen isimdir. Bu makinenin bulunduğu kısmı iklimlendiren klima ünitesi ise ring kliması olarak isimlendirilmektedir. Şekil 1'de iplik üretim tesisinde makine ve pleytlerin konumlandırılması paylaşılmıştır. Analizlerde mevcut durumda kullanılan pleyt yapısı dahil olmak üzere 4 farklı pleyt kanat yapısı kullanılmıştır. Analizler boyunca pleyt kanatları üzerinden hava akışının homojenliği ve ortam havasına etkisi irdelenmiştir.

\subsection{Pleytli üfleme menfezi}

Sayısal analizlerde kullanılan pleytli üfleme menfez geometrisi Şekil 2'de verilmiştir. Yapılan çalışmada Pleytli üfleme menfezi hava giriş kesiti ölçüleri $840 \mathrm{~mm}$ x $220 \mathrm{~mm}$, kontrol hacmi ölçüleri $1000 \mathrm{~mm}$ x $1250 \mathrm{~mm} \times 750 \mathrm{~mm}$ dir. Difüzörün çıkışından $200 \mathrm{~mm}$ uzaklığa pleyt monte edilmiştir.
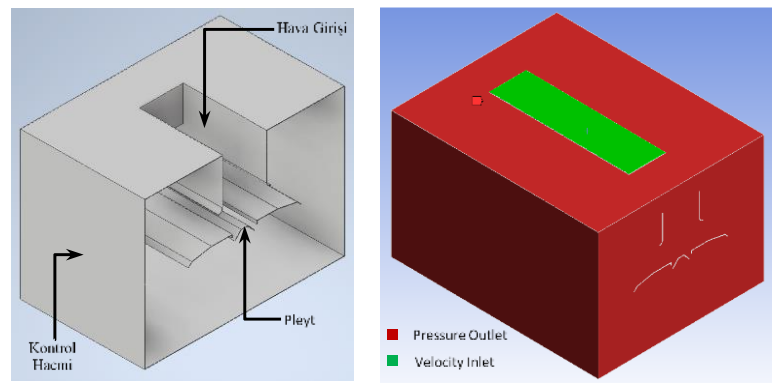

Şekil 2. Pleytli üfleme menfezi
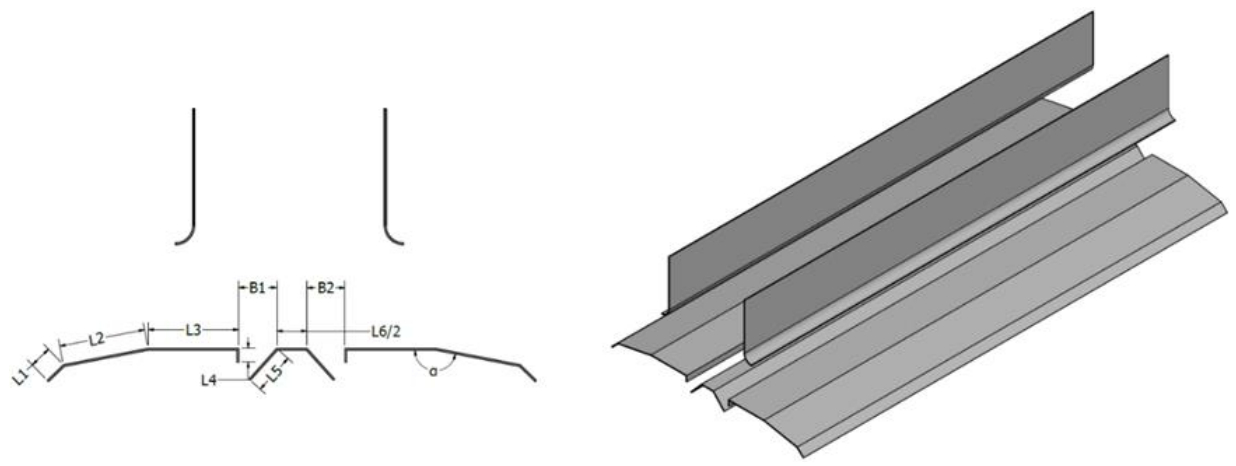

Şekil 3. Mevcut tasarım
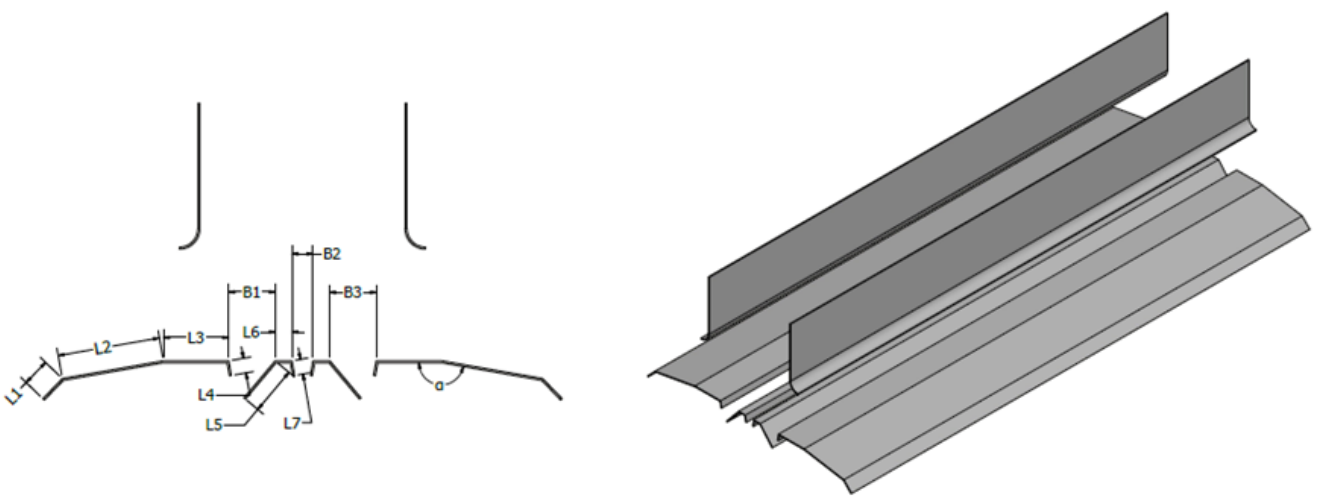

Şekil 4. Tasarım 1 

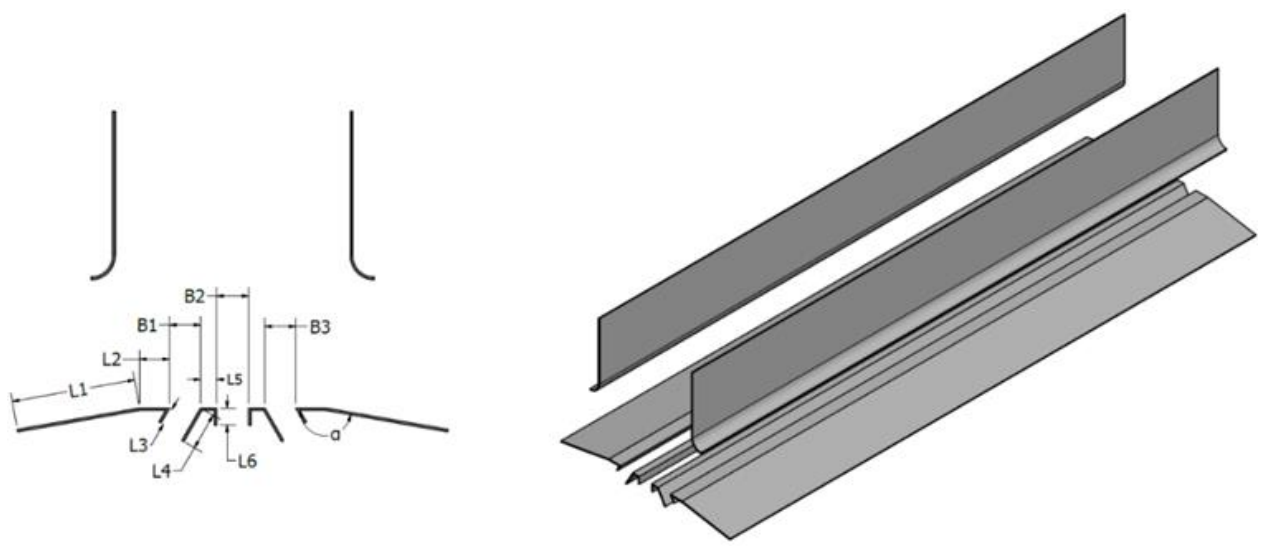

Sekil 5. Tasarım 2
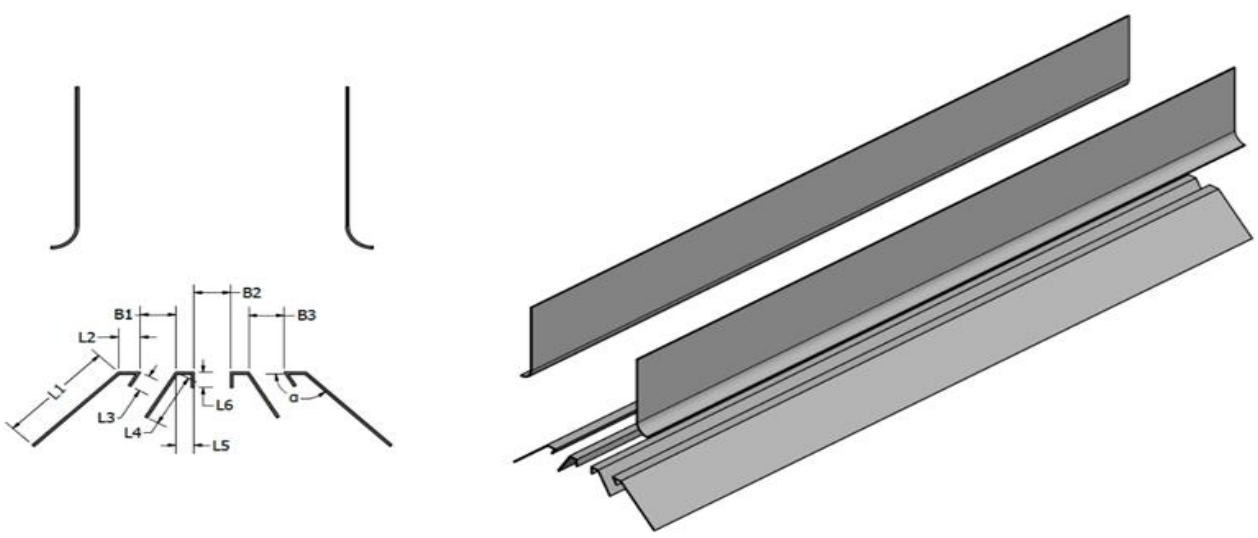

Şekil 6. Tasarım 3

\subsection{Saylsal modelleme}

Oluşturulan pleyt tasarımlarının akış analizleri ANSYS 19.2 programında gerçekleştirilmiştir. Havanın difüzöre girdiği kesit 'velocity-inlet (hız girişi)' kontrol hacmi 'atmosfer' olarak isimlendirilmiş ve 'pressure outlet (basınç çıkışı)' sınır şartı verilmiştir (Tablo 2). Difüzör ve pleyt 'wall-plate' sınır şartı tanımlanmıştır. Hız sınır şartı olarak girilen değer, çalışan bir tekstil klima sistemi menfezlerinden ölçülen değerdir. Mesh yapısı ve kesit görünüşleri Şekil 7'de verilmiştir.

Tablo 2. Sınır şartları

\begin{tabular}{cc}
\hline Kesit & Sınır Şartı \\
\hline Velocity-inlet (Hız girişi) & $2.25 \mathrm{~m} / \mathrm{s}$ \\
Pressure Outlet (Kontrol hacmi) & $0 \mathrm{~Pa}$ \\
\hline
\end{tabular}

Ağ yapısının kalitesi sayısal çözümlemenin kararlılığı ve doğruluğu üzerinde önemli rol oynamaktadır. Ağ kalitesinin önemli bir göstergesi ortogonal kalitedir. Ortogonal kalite, hücrenin ağırlık merkezinden her bir yüzeyine karşılık gelen yüzey alanı vektörü ile birlikte hücrenin ağırlık merkezinden bitişik hücrelerin ağırlık merkezlerine olan vektörler kullanılarak hesaplanır [11].

En kötü hücreler 0'a, en iyi hücreler ise 1'e daha yakın bir ortogonal kaliteye sahiptir. Tüm hücreler için ortogonal kalite 0.01 'den fazla olmalı ve ortalama kalite ise bu değerden daha yüksek olmalıdır [11]. Tasarımların ağ kaliteleri Tablo 3'te verilmiştir.
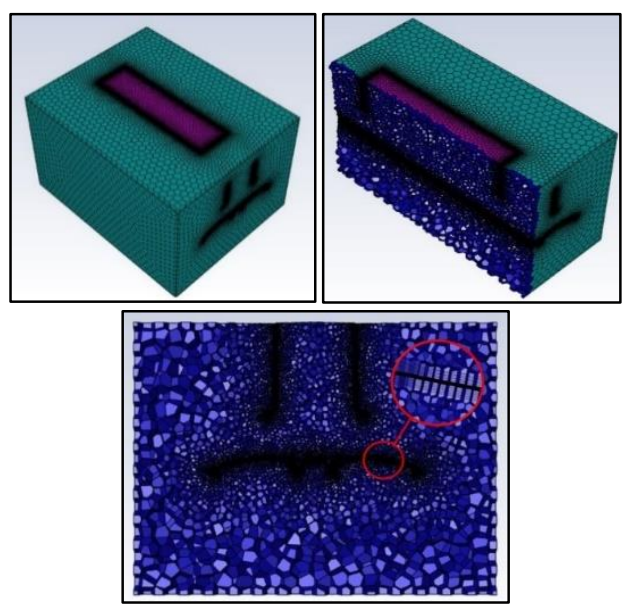

Şekil 7. Ağ yapısı ve kesit görünüşleri

Tablo 3. Pleyt tasarımlarının ağ kalitesi

\begin{tabular}{ccc}
\hline Pleyt Tasarımı & Eleman Sayısı & Maks. Çarpıklık \\
\hline Mevcut & 2862351 & 0.80 \\
1 & 2932157 & 0,80 \\
2 & 2726852 & 0,79 \\
3 & 3203118 & 0,79 \\
\hline
\end{tabular}


Çarpıklık, herhangi bir hücrenin geometrisiyle eşdeğer hacme sahip bir başka hücrenin geometrisi arasındaki fark olarak tanımlanmaktadır. Çarpık (çok eğimli) hücreler çözümün doğruluğunu azaltıp, istikrarsızlaştırabilir. Örneğin, dörtgen geometriye sahip ağlar 90 dereceye yakın köşe açılarına sahipken, üçgen hücreler tercihen 60 dereceye yakın açılara veya 90 dereceden daha az açılara sahip olmalıdır. Genel kural, çoğu akışta üçgen veya dörtgen ağ yapıları için maksimum çarpıklığın 0.95 'in altında tutulması gerektiği ve ortalama çarpıklığın ise 0.95 'ten daha düşük olması gerektiğidir [11]. Yapılan çalışmada çarpıklık değerleri $0.79-0.80$ aralığında olup, kabul edilebilir bir değere sahiptir.

Kullanılacak ağ yapısının kalitesi analiz sonuçlarının doğruluğunu önemli ölçüde etkilemektedir. Uygun ağ yapısını belirlemek için ağ iyileştirme çalışması yapılmıştır. Farklı eleman boyutlarının bulunduğu ağ yapılarındaki modeller ANSYS programında analiz edilerek optimum ağ yapısı belirlenmiştir. Tablo 4'te yapılan ăg iyileştirme çalışması sonuçları gösterilmiştir. Tabloda görüldüğü gibi 2.5 milyon - 3.2 milyon arası eleman sayıları kabul edilebilir hata oranına sahiptir. $\mathrm{Bu}$ durum dikkate alınarak yapılan çalışmalarda bu aralıktaki eleman sayıları kullanarak ağ yapıları oluşturulmuştur. Akış analiziyle ilgili birçok çalışma incelenmiş ve bu tür çalışmalarda standart k-E türbülans modeli tercih edildiği görülmüştür [1-4, 7-9]. Bu çalışmada da k-E türbülans modeli kullanılmıştır.

Tablo 4. Üçüncü tasarım için ağ bağımsızlık çalışması

\begin{tabular}{ccccc}
\hline Deneme & $\begin{array}{c}\text { Eleman } \\
\text { Sayısı }\end{array}$ & $\begin{array}{c}\text { Maks. } \\
\text { Çarpıklı }\end{array}$ & $\begin{array}{c}\text { Orta } \\
\text { Boşluktaki } \\
\text { Ortalama Hız } \\
(\mathrm{m} / \mathrm{s})\end{array}$ & $\begin{array}{c}\text { Hata Oranı } \\
(\%)\end{array}$ \\
\hline 1 & 1578607 & 0.7999 & 0,6562 & \\
2 & 1828741 & 0,7998 & 0,6414 & 2,25 \\
3 & 2197786 & 0,7961 & 0,5868 & 8,51 \\
4 & 2547845 & 0,7970 & 0,5715 & 2,61 \\
5 & 3203118 & 0,7977 & 0,5655 & 1,05 \\
\hline
\end{tabular}

\subsubsection{Standart $k$ - $\varepsilon$ türbülans modeli}

İki denklemli türbülans modelleri içerisinde birçok akış çözümlemesinde kabul edilebilir sonuçlar vermesi bakımından yaygın olarak kullanılan yarı ampirik bir türbülans modelidir. Model, türbülans kinetik enerjisi (k) ve kayıp oranı $(\varepsilon)$ için yazılan iki transport denkleminin çözümü ve türbülans viskozitesinin $(\mu t)$ hesabını içermektedir.
Kaldırma kuvvetlerinin etkisi ihmal edildiğinde, bu transport denklemleri k ve $\varepsilon$ için sırası ile Denklem 1 ve Denklem 2'de verilen şekilde yazılabilir [3].

$$
\begin{aligned}
\frac{\partial(\rho k)}{\partial t}+\frac{\partial\left(\rho k u_{i}\right)}{\partial x_{i}} & =\frac{\partial}{\partial x_{i}}\left[\left(\mu+\frac{\mu_{t}}{\sigma_{k}}\right) \frac{\partial k}{\partial x_{j}}\right]+G_{k}-\rho \varepsilon \\
\frac{\partial(\rho \varepsilon)}{\partial t}+\frac{\partial\left(\rho \varepsilon u_{i}\right)}{\partial x_{i}} & =\frac{\partial}{\partial x_{i}}\left[\left(\mu+\frac{\mu_{t}}{\sigma_{k}}\right) \frac{\partial k}{\partial x_{j}}\right]+C_{1 \varepsilon} \frac{\varepsilon}{k} G_{k} \\
& -C_{2 \varepsilon} \rho \frac{\varepsilon^{2}}{k}
\end{aligned}
$$

\subsection{Deneysel çalı̧̧ma}

Çalışma kapsamında, kullanılan deney düzeneğinin şematik görünümü Şekil 8'de verilmiştir. Düzenek hava akışını sağlayan $11 \mathrm{~kW}$ motor gücüne sahip salyangoz fan, akışın düzleştirilmesi için kullanılan akış düzenleyiciler, hava kanalı, akışın pleyt üzerine yönlendirilmesini sağlayan difüzör ve akış yönlendirici pleytler olmak üzere 5 ana kısımdan oluşmaktadır. Sayısal çalışmada kullanılan sınır koşulları düzenekte sağlanarak, pleyt orta boşluğunda anemometre ile hava hızı taraması yapılmıştır. Hız ölçümlerinde Cem DT-619 model pervaneli tip anemometre kullanılmıştır Hız taraması sonucunda pleyt boşluğunda çıkan ortalama hava hızı tespit edilmiş olup, sayısal modellemenin mesh bağımsızlık çalışmasında aynı düzlemden alınan ortalama hız ile karşılaştırılmıştır. Elde edilen veriler Tablo 5 'te paylaşılmıştır.

Tablo 5. Üçüncü tasarım için deneysel doğrulama

\begin{tabular}{lcc}
\hline Çalı̧̧ma Tipi & $\begin{array}{c}\text { Orta Boşluktaki } \\
\text { Ortalama Hız } \\
(\mathrm{m} / \mathrm{s})\end{array}$ & $\begin{array}{c}\text { Hata Oranı } \\
(\%)\end{array}$ \\
\hline Sayısal & 0,56 & 5,36 \\
\hline Deneysel & 0,53 & \\
\hline
\end{tabular}

\section{Bulgular ve tartışma}

$\mathrm{Bu}$ çalışmada, pleytli üfleme menfezlerinde akışın ortama homojen yayılmasını sağlayan farklı pleyt tasarımlarının akışa etkisi sayısal olarak incelenmiştir. Difüzörden çıkan havanın, pleyt kullanarak işletme ortamına homojen bir şekilde genişletilmesi hedeflenmiştir.
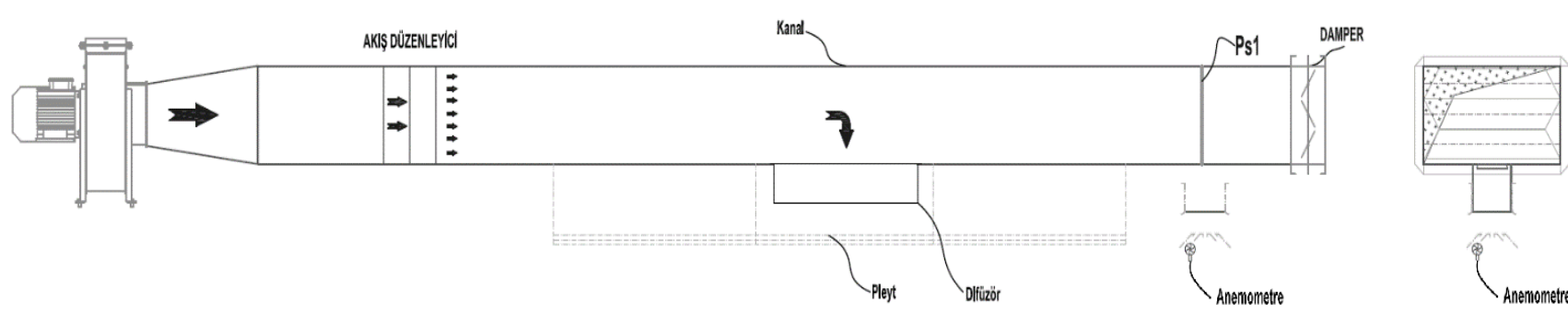

Şekil 8. Deney düzeneği 
Benzer çalışmalar 1şı̆̆ında türbülans modeli olarak standart k- $\varepsilon$ seçilmiştir. A $\breve{g}$ yapısını eleman boyutlarını değiştirerek gerçeğe daha yakın sonuçlar veren ağ yapısı belirlenmiş ve sayısal çalışmalarda kullanılmıştır.

Şekil 9'da, mevcut pleyt tasarımı üzerinden olan akışın dağılımı verilmiştir. Akışın geniş açıda ortama yayılması ve akışın aşağı inememesi, ortamdaki uçuntuları artıracak ve üretim sürecini olumsuz yönde etkileyecektir. Pleyt kanatları altında vorteksler oluşmakta ve bu sebeple akışta geri dönüşler olmaktadır. Pleyt üzerindeki hava jetinden kaynaklı orta kesitten çıkan akış kenarlara doğru yönlenmektedir. $\mathrm{Bu}$ durumdan dolayı iplik tozları yukarı doğru hareket etmekte ve işletme içerisindeki toz uçuntu oranı artmaktadır.

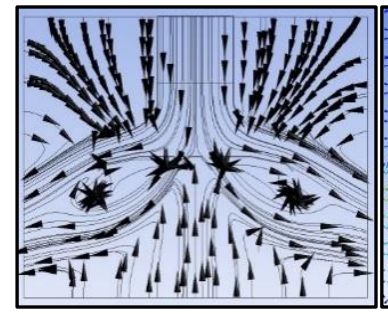

(a)

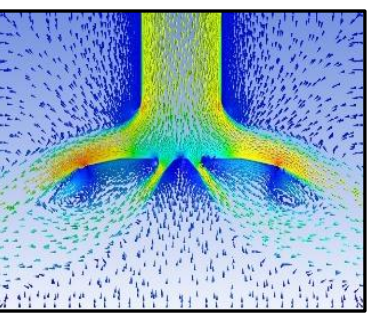

(b)
Şekil 9. Mevcut tasarım üzerinde akış dağılımı ((a) akış çizgileri (b) vektörel dağılım)

Tasarım 1 için yapılan analiz sonucunda elde edilen akış görüntüleri Şekil 10'da verilmiştir. Pleyt üzerinde oluşan hava jetinden kaynaklı olarak, pleyt altında hava geri dönüşleri meydana gelmiştir. Bu tasarımın kullanılması durumunda da ortamda bulunan iplik ve elyaf tozları hava akımından olumsuz olarak etkilenecekler ve yukarı doğru yönlenecektir. $\mathrm{Bu}$ durum ürün (iplik) kalitesini ve verimliliğini olumsuz yönde etkileyecektir.

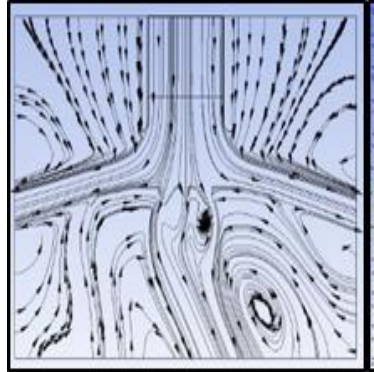

(a)

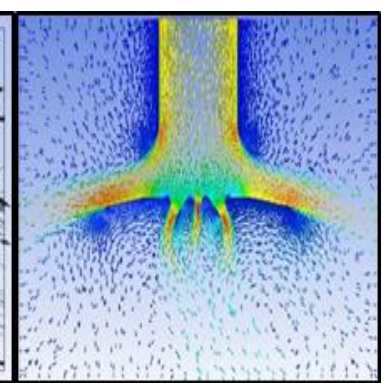

(b)
Şekil 10. Tasarım 1 üzerinde akış dağılımı ((a) akış çizgileri (b) vektörel dağılım)

Tasarım 2 için elde edilen sonuçlar da tasarım 1 için elde edilen sonuçlara benzer davranıș sergilemiștir (Şekil 11). Tasarım 1'in ortasında bulunan 3 boşluklu yapının geometrik boyutları değiştirilmesine rağmen ortadaki boşluktan hava jeti oluştuğundan, kenarlardaki hava çıkışı ortaya yönlenmiş ve iplik üretim hattına doğru hava jeti oluşmuştur. Oluşan hız vektörleri incelendiğinde, pleyt üzerindeki hava jetinden kaynaklı olarak ortamda ters dönüşler meydana gelmiştir. $\mathrm{Bu}$ sonuçla, ortamdaki uçuntuların havada kalma süresinin uzayacağ 1 tahmin edilmektedir.

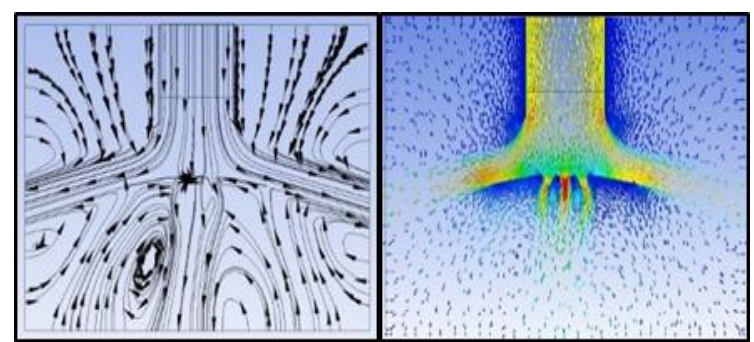

(a)

(b)

Şekil 11. Tasarım 2 üzerinde akış dağılımı ((a) akış çizgileri (b) vektörel dağılım)

Tasarım 3 için elde edilen akış analizi Şekil 12'de verilmiştir. Akış analizi incelendiğinde, havanın aşağı doğru yönlenmesiyle ortamdaki uçuntuların da aşağı doğru yönleneceği görülmektedir. Pleyt üzerinde boşluklar optimize edilerek daha homojen bir dağılım elde edilmesi mümkündür. $\mathrm{Bu}$ tasarım ile, ortamdaki uçuntuların havada asılı kalma süresinin diğer pleyt tasarımlarına göre daha az olacağı anlaşılmaktadır. Ayrıca diğer tasarımlara göre daha dar kanat açısına sahip olduğundan dolayı difüzörden çıkan akış rahat bir şekilde yönlenip basınç kaybını azaltarak enerji tasarrufu sağlayacaktır.

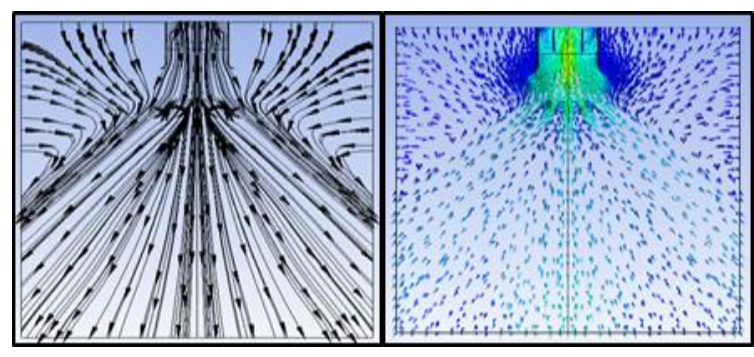

(a)

(b)

Şekil 12. Tasarım 3 üzerinde akış dağılımı ((a) akış çizgileri (b) vektörel dağılım)

\section{Sonuçlar}

Bu çalışmada tekstil iplik üretim tesislerinde kullanılan klima santrallerinin üfleme menfezlerinde akışın ortama homojen yayılmasını sağlayarak işletme içerisindeki iplik tozlarının (uçuntu) emiş slotlarına yönlendirilmesini sağlayan pleyt yapıları üzerinde çalışılmış ve pleytin akış üzerindeki etkisi sayısal olarak incelenmiştir.

Pleyt merkezlerinde boşluklu bir yapının bulunması halinde merkezdeki pleyt kanatlarına açı verilerek yayıcılık özelliği kazandırılmasının akışın homojen yayılmasını etkileyen bir parametre olduğu tespit edilmiştir.

Tasarımlarda pleyt merkezine kanat bırakılarak pleytin $\mathrm{x}$ eksenindeki uzunluğu artırıldığında akışın olumsuz olarak etkilendiği ve ortamdaki akışta ters dönüşler oluşacağı sonucuna varılmıştır.

Pleyt merkezlerine bırakılacak boşluklarının doğru tayin edilmesi ve bu boşluklarının difüzörden çıkan hava akış hızına bağlı olarak optimum boşluk mesafesinin belirlenmesi gerektiği düşünülmektedir.

Tekstil işletmeleri iplik üretim ve dokuma tesislerinin üretim şartları ve ortam isterleri dikkate alınarak mevcut 
durum ve 3 farklı pleyt tasarımın akış yapıları karşılaştırıldığında $135^{\circ}$ kanat açısına sahip 4 kanatlı tasarım 3'ün, menfezlerden çıkan hava akışını üretim alanına daha homojen bir şekilde yaydığı ve istenmeyen akış yapılarının meydana gelmediği görülmüştür.

\section{Çıkar çatışması}

Yazarlar çıkar çatışması olmadığını beyan etmektedir.

Benzerlik oranı (iThenticate): $\% 17$

\section{Kaynaklar}

[1] A. Yıldırım, C. Özalp, M. Söyler ve E. Hürdoğan. İklimlendirme sistemlerinde kullanılan farklı tip menfez ve difüzörlerin yerleşimi, jet nozulun hız dağılımlarının incelenmesi. Osmaniye Korkut Ata Üniversitesi Fen Bilimleri Enstitüsü Dergisi. 1(1): 2227, 2018.

[2] A. Kaya, M.S. Kamer, K. Sönmez ve A.V. Vakkasoğlu, Klima santrallerindeki boş hücreler için tasarlanan bir anemostat tip difüzörün akış analizi. IV. Uluslararası Katılımlı Anadolu Enerji Sempozyumu, sayfa 1266, Edirne, Türkiye, 18-20 Nisan 2018.

[3] M. S. Kamer, K. Sönmez ve A. Kaya. Farklı kesit genişlemeli geometrilerin klima santralleri için tasarlanan bir anemostat tip difüzörlü boş hücredeki akışa etkisinin sayısal olarak incelenmesi. Selçuk Üniversitesi Mühendislik, Bilim ve Teknoloji Dergisi, 6(4): 694-711 2018. https://doi.org/10.15317 /Scitech.2018.161

[4] Ş. Yiğit, C. Sungurlu ve B. Çuhadaroğlu, HVAC sistemlerinde kullanılabilecek yeni tip bir difüzör için performans incelemesi, 11. Ulusal Tesisat
Mühendisliği Kongresi, sayfa 19-36. İzmir, Türkiye, 17-20 Nisan 2013.

[5] A. Patel, P. S. Dhakar, CFD Analysis of air conditioning in room using Ansys Fluent. Journal of Emerging Technologies and innovative Research, November 2018, Madhya Pradesh, India, 5 (11): 436 4412018.

[6] G. Kuas ve Ş. Başkaya. Havalandırılan bir ofis odasında hava hareketinin sayısal analizi. Gazi Üniversitesi Mühendislik Mimarlık Fakültesi Dergisi. 17 (2): 35 - 522002.

[7] E. Öntaş, Kapalı hacimlerde slot difüzör kullanımının hava dağılımına etkisi. Yüksek Lisans Tezi. İstanbul Teknik Üniversitesi Fen Bilimleri Enstitüsü. İstanbul, Türkiye, 2008.

[8] B. E. Yüce ve E. Pulat, Bir ofis odasındaki termal akışın kış şartlarında sayısal olarak incelenmesi, 13. Ulusal Tesisat Mühendisliği Kongresi. İzmir, Türkiye, 19-22 Nisan 2017.

[9] A. S. Canbolat, Ö. Kaynaklı, B. Türkan ve N. Yamankaradeniz. Klima cihazı üfleme çıkış açısının 1sıl konfor üzerindeki etkisinin nümerik olarak incelenmesi, 13. Ulusal Tesisat Mühendisliği Kongresi, sayfa 1203-1213, İzmir, Türkiye, 19-22 Nisan 2017.

[10] A. Awwad, M. H. Mohamed and M.Fatouh. Optimal design of a louver face ceiling diffuser using CFD to improve occupant's thermal comfort, Journal of Building Engineering, 11(1): 134-157, 2017. http://dx.doi.org/10.1016/j.jobe.2017.04.009

[11] Ansys, Inc. ANSYS Fluent User's Guide. Canonsburg, PA, 2013. 